\title{
Su sabor provoca... análisis de transitividad y subjetividad en anuncios publicitarios*
}

\author{
ALKYS LAMAS \\ alkyslamas@gmail.com
}

Recepción: 05 de mayo de 2015

Aprobación: 12 de junio de 2015

Forma de citar este artículo: Lamas, A. (2015). Su sabor provoca... análisis de transitividad y subjetividad en anuncios publicitarios. Cuadernos de Lingüística Hispánica, 26, 121-138, Tunja: Uptc.

* Artículo de investigación científica.

** Profesora de Lengua y Literatura, Magíster en Linguística por la Universidad Experimental Libertador - Maracay (Venezuela) y Candidata a Doctora por la Universidad Católica Andrés Bello - Caracas (Venezuela). Docente categoría Asistente de la Universidad Pedagógica Experimental Libertador - El Mácaro, sede Aragua (Venezuela). Miembro activo de la línea de investigación "El Español de Venezuela" del Centro de Investigaciones Lingüísticas y Literarias "Hugo Obregón Muñoz", UPEL - Maracay, sede Aragua (Venezuela). Premio "Andrés Bello" a la Investigación Linguística (Academia Venezolana de la Lengua, edición año 2011). 


\section{Resumen}

El lenguaje publicitario responde a operaciones lingüísticas no neutrales que se orientan eminentemente a causas que median entre las limitantes de espacio, la obligatoriedad de proporcionar al consumidor una idea exacta del producto y el apego a los valores connotativos y recursos retóricos. La presente investigación analiza los procedimientos sintácticos empleados en un conjunto de 15 anuncios publicitarios seleccionados. Se considera: a) la transitividad y su aplicación en esquemas sintácticos manifiestos en los anuncios publicitarios, y b) la inserción de la persona como estrategia sintáctica y discursiva. Entre los resultados obtenidos destacan: el empleo predominante del predicativo y del adjetivo adverbializado, aplicación recurrente de fórmulas de tratamiento y la reflexividad, alta frecuencia en el registro de uso de esquemas sintácticos transitivos y preeminencia de la distinción de cualidades o atribuciones por el emisor/ publicista hacia el receptor/comprador, y preeminencia de sustantivos y adjetivos relativos al condicionamiento de la existencia del receptor/comprador.

Palabras clave: transitividad, subjetividad, anuncios publicitarios.

\section{Its flavor tempts... Analysis of subjectivity and transitivity in advertisements}

\section{Abstract}

Advertising language responds to non-neutral language eminently oriented operations to causes that mediate between the limitations of space, the obligation to provide the consumer with an exact idea of the product and adherence to the connotative values and rhetorical devices. This research analyzes the syntactic procedures used in a set of 15 selected advertisements. It is considered: a) transitivity and its application in syntactic patterns manifest in advertisements; and, b) the inclusion of the person as syntactic and discursive strategy. Among the results are: the predominant use of predicative and adjective adverb function, and recurrent treatment applying formulas and reflexivity, high frequency recording transitive use of syntactic patterns and preeminence of the distinction of qualities or powers by the issuer / publicist to the receiver / buyer and preeminence of nouns and adjectives related to the conditioning of the existence of the receiver / buyer.

Key words: transitivity, subjectivity, advertisements. 


\section{Sa saveur provoque... analyse de transitivité et subjectivité dans des annonces publicitaires}

\section{Résumé}

Lelangage publicitaire répond aux opérations linguistiques non neutres quis'orientent éminemment vers des causes qui s'interposent entre les limitations de l'espace, le caractère obligatoire de fournir une idée exacte du produit au consommateur, et l'attachement aux valeurs connotatives et les ressources rhétoriques. Cette recherche analyse les processus syntaxiques employés dans un ensemble de quinze annonces publicitaires sélectionnés. On considère: a) la transitivité et son application aux schémas syntaxiques manifestes dans les annonces publicitaires, b) l'insertion de la personne en tant que stratégie syntaxique et discursive. Entre les résultats obtenus, on remarque: l'emploi prédominant du prédicatif et de l'adjectif adverbialisé ; l'application récurrente des formules de traitement et la réflexivité ; une haute fréquence dans le registre d'utilisation de schémas syntaxiques transitifs et, la prééminence de la distinction de qualités ou attributions par l'émetteur/ publiciste vers le récepteur/acheteur ; et la prééminence de noms et d'adjectifs relatifs au conditionnement de l'existence du récepteur/acheteur.

Mots clés: transitivité, subjectivité, annonces publicitaires.

\section{Seu sabor provoca... análise de transitividade e de subjetividade em anúncios publicitários}

\section{Resumo}

A linguagem publicitária responde a operações linguísticas não neutrais que se orientam eminentemente a causas que mediam entre as limitantes de espaço, a obrigatoriedade de proporcionar ao consumidor uma ideia exata do produto e 0 apego aos valores conotativos e aos recursos retóricos. A presente pesquisa analisa os procedimentos sintáticos empregados em um conjunto de 15 anúncios publicitários selecionados. Considera-se: a) a transitividade e sua aplicação em esquemas sintáticos manifestos nos anúncios publicitários, e b) a inserção da pessoa como estratégia sintática e discursiva. Entre os resultados obtidos destacam-se: o emprego predominante do predicativo e do adjetivo adverbializado, aplicação recorrente de fórmulas de tratamento e a reflexividade, alta frequência no registro de uso de esquemas sintáticos transitivos e preeminência da distinção de qualidades ou atribuições pelo emissor/publicitário para o receptor/ comprador, e preeminência de substantivos e adjetivos relativos ao condicionamento da existência do receptor/comprador.

Palavras chave: transitividade, subjetividade, anúncios publicitários. 


\section{Introducción}

En los anuncios publicitarios, el análisis sintáctico conforma una alternativa de indagación que dé cuenta de los niveles de afectación que recibe un receptor de tales anuncios y que, a su vez, determine tanto los esquemas sintácticos extraídos de estructuras oracionales de los anuncios publicitarios, así como las actitudes mentales impulsoras de subjetividad eminentemente promovida por el emisor/hablante. En este sentido, la presente investigación se fundamenta en un acercamiento a los procedimientos sintácticos que evidencien las varias funciones sintácticas desempeñadas por los actantes en el discurso publicitario, considerando: a) uso de esquemas sintácticos; b) clases semánticas de verbos así como de número y de persona. Es así como la aproximación a estas prácticas instan consecuentemente a examinar la relación vinculante entre: i) la efectividad del uso del lenguaje publicitario; ii) las necesidades comunicativas del emisor/hablante (publicista) apoyadas en las normativas de libertad creacional y de la economía informativa, y iii) la transitividad verbal como evidencia de generación de patrones de subjetividad y formas estratégicas de la inserción de la persona.

\section{Fundamentación teórica}

\subsection{Motivos para la transitividad}

Al comprender, en un sentido estructural la presentación de la transitividad, se apela a caracterizarla no solo por su acompañamiento de un complemento directo, sino que además este último, no le debe preceder la preposición "a" ya que se catalogaría el caso como intransitivo. No obstante, dada la alta injerencia del hablante en la construcción de patrones sintácticos, la transitividad o intransitividad figurarían como opciones producto de intereses u objetivos cimentados en bases discursivas o, pragmático - semánticas. Pero en lo que concierne a la transitividad, no todo refiere a ámbitos de índole semánticos, existen opciones sintácticas que se prestan como soportes teóricos y metodológicos frente a vacilaciones de "transitividad - intransitividad". Porto - Dapena (1994) apunta que todos los tipos de complementos, aparte de disponer de una caracterización en lo 
estricto operacional, cuentan además con una apreciación funcional que se diferencia de la sola estructura sintáctica, lo cual se traduce en que, la opcionalidad sintáctica de un complemento no siempre se corresponde con la opcionalidad de tipo semántica.

En lo que refiere al "Complemento Directo" o "Implemento", Porto - Dapena (1994) lo define como "[...] el primer complemento del verbo, esto es, el elemento que lo modifica o completa en primer lugar." (p. 18). Señala el autor además, la vinculación del complemento directo con la transitividad, entendida ésta como: “...propiedad semántico - sintáctica que poseen algunos verbos [... ], expresa una acción o proceso que, partiendo de un agente $\mathrm{u}$ origen, pasa $\mathrm{o}$ se dirige a un paciente $\mathrm{o}$ término.

La transitividad, entonces, pautaría la elaboración de todo patrón oracional, incluso, de todo patrón semántico interpretativo de la realidad. El objeto indirecto se involucra en la transitividad "por cuanto que, en contextos transitivos, su incidencia con el verbo se produce, [...] a través del objeto directo" (Porto Dapena, 1994, p. 26); es así como, en términos nocionales, sin transitividad no hay lugar a la intransitividad con motivo de que quien recibe de manera indirecta los efectos de una acción, solo los recibe puesto que siempre existe un alguien o un algo que la materializa, aunque esto implique un determinado nivel de abstracción en el que se vea sujeta la transitividad.

\subsection{Los esquemas sintácticos en anuncios publicitarios}

El carácter motivado de las estructuras lingüísticas persigue la codificación de los estados de cosas mediante la confección de diferentes esquemas construccionales. Estos esquemas promueven no solo la correspondencia entre los usuarios del sistema de la lengua, de manera que la construcción particular de una situación también particular, insta a la selección, utilización y reutilización de tales construcciones con base en su eficacia comunicativa según diferentes contextos. Pero, la frecuencia de uso de estos esquemas de construcción en una lengua estimula la cuantificación y caracterización de las interpretaciones lingüísticas y extralingüísticas que portan estas construcciones, lo cual además incluye las probabilidades de uso que estas pueden tener y los valores sintácticos y semánticos variables entre diferentes géneros discursivos.

García - Miguel (1995, p. 36) expone la definición de "esquema sintáctico" como "el conjunto de funciones sintácticas desempeñadas por los actantes en una cláusula determinada [...]", a esto agrega que:

En mi opinión, resulta viable concebir los esquemas clausales como modos de presentar sintácticamente las relaciones semánticas existentes entre predicado y actantes y, en consecuencia, entender que los esquemas sintácticos, en tanto que 
moldes organizativos, son relativamente independientes de los elementos léxicos que los integran. Esto no impide la existencia de asociaciones convencionales (fijadas entre un lexema verbal y ciertos esquemas sintácticos. Desde el punto de vista semántico, esto quiere decir que en una cláusula debemos tener en cuenta el significado aportado por el esquema) (p. 37).

Considerando a la transitividad como "noción multifactorial”, Vázquez Rozaz y García - Miguel (2005) estiman en ella factores relevantes, tales como: el número de participantes, propiedades generales del proceso como la dinamicidad y telicidad, la naturaleza del agente y la afección e individualización del paciente; pero mucho más relevante aún lo es -para efectos de estudio y análisis de esquemas sintácticos- que estos constituyen combinaciones de "[...] posiciones estructurales que son ocupadas (0 especificadas) por material léxico o gramatical, cabrían tanto esquemas sintácticos como combinaciones posibles de funciones sintácticas nucleares”.

Una alternativa que permite reunir los esquemas sintácticos correspondientes con la lengua española, se representa mediante:

Tabla 1. Esquemas sintácticos más frecuentes en español

\begin{tabular}{|c|l|}
\hline VALENCIA & ESQUEMA SINTÁCTICO \\
\hline $\mathbf{0}$ & PREDICADO \\
\hline $\mathbf{1}$ & SUJ - PRED \\
& PRED - CDIR \\
\hline \multirow{2}{*}{$\mathbf{2}$} & SUJ - PRED - CDIR \\
& SUJ - PRED - CADV \\
& SUJ - PRED - SUPL \\
& SUJ - PRED - CIND \\
\hline \multirow{3}{*}{} & SUJ - PRED - CDIR - CIND \\
& SUJ - PRED - CDIR - CADV \\
& SUJ - PRED - CDIR - SUPL \\
& SUJ - PRED - CIND - SUPL \\
\hline
\end{tabular}

Fuente: García - Miguel, J. M. (1995) Las relaciones gramaticales entre Predicado y Participantes, p. 38).

Agrupados los esquemas sintácticos según la valencia cuantitativa 0 , número de actantes que es susceptible de regir, se tienen pautas en el español de verbos sin actantes (avalentes), con un actante (monovalente), con dos actantes (bivalentes) y con tres (trivalentes). Con ello, se pretende atenuar la tajante división de verbos en las categorías de "transitivos" e "intransitivos" brindándole gradaciones para su comprensión usual. 
A propósito de la explicación y caracterización del uso de los esquemas sintácticos en los anuncios publicitarios, es pertinente la enumeración de algunos comportamientos que manifiestan estos esquemas en respuesta a dos objetivos neurales para la publicidad:

1. Con base en la perspectiva emisor/hablante, a sabiendas, el publicista y el empresario, se obtiene el esquema general:

- Alguien oferta/publicita algo, equivalente a SUJVCD

- Estructura que es de estimársele como [+ Transitividad], ya que su función sintáctica y discursiva instan a la indicación y descripción de acciones o eventos.

2. Con base en la perspectiva del receptor/oyente, a sabiendas, el comprador o consumidor, se obtiene el esquema general:

- Alguien compra/adquiere algo + [para algún fin; 0, por alguna causa, motivación impuesta o fomentada], equivalente a:
i. SUJVCI
ii. SUJVCISUPL
iii. SUJVCICCIRC

3. Estructura que es de estimársele como [- Transitividad] o [+ Intransitiva].

4. La direccionalidad que asumen los anuncios publicitarios se enfoca en la figura del "Tú" o del "Usted".

5. Predominio de la segunda persona del singular. En ocasiones, se presenta un sujeto tácito en las oraciones, aunque se presta apoyo de los pronombres antepuestos al verbo, tales como: te, se, le.

6. Los verbos se presentan en forma imperativa, aunque esta última matizada de "sugerencias" con pocas posibilidades de rechazo o contraposición del receptor.

\subsection{Clasificación semántica de los verbos}

A toda la información sintáctica planteada anteriormente, se le suma una información semántica tomada de la "Lista provisional de clases verbales ADESSE («Alternancias de diátesis y esquemas sintáctico semánticos del español»), mediante la cual se pretende proporcionar una explicación que conjugue sentidos verbales, clases de verbos y roles 
semánticos a la par de su co -ocurrencia con esquemas sintácticos. Tales procedimientos permitirán explicar la frecuencia de uso de:

1. Verbos inscritos en determinados esquemas de construcción.

2. Esquemas de verbos pertenecientes a una o varias clases semánticas (según obedezcan sus comportamientos a funciones sintácticas o semánticas no correspondientes la una con la otra).

3. Clases semánticas de los verbos registrados en un esquema sintáctico.

4. Correlación de estas clases semánticas de los verbos con la valoración discursiva de la subjetividad en el anuncio publicitario.

Respecto de la "Lista Provisional de Clases Verbales" ya mencionada, se han tomado en consideración -para efectos del lenguaje publicitario presente en anuncios comerciales-, seis (06) tipos de macroclases verbales, los cuales responden a los cometidos inherentes a los procesos de iconización y subjetivización de productos, conductas y comportamientos pre-estimados en este sentido; se parte del hecho de considerar como factor determinante de la comunicación publicitaria al receptor y todos sus estímulos conductuales.

Así, se consideran las siguientes macroclases conjunto con algunas clases, subclases y verbos puntuales que esquematizan e introducen -globalmente- en los anuncios publicitarios objetos de estudio:

Tabla 2. Selección de clases verbales (según lista ADESSE)

\begin{tabular}{|c|c|c|c|}
\hline MACROCLASE & CLASE & SUBCLASE & VERBOS \\
\hline \multirow{2}{*}{ Proceso mental } & Mental general & & Adivinar; predeterminar; sentir. \\
\cline { 2 - 4 } & Cognición & Creencia & Creer; opinar. \\
\hline \multirow{2}{*}{ Proceso relacional } & Atribución & General & Parecer; semejar; ser. \\
\cline { 2 - 4 } Conductas & Posesión & Pertenencia & Adquirir; disponer; tener. \\
\hline \multirow{2}{*}{ Proceso verbal } & Comportamiento & $\begin{array}{c}\text { Relaciones } \\
\text { Sociales }\end{array}$ & $\begin{array}{c}\text { Aceptar; admitir; aprobar; proteger; } \\
\text { recibir; valorar. }\end{array}$ \\
\hline \multirow{2}{*}{ Proceso existencial } & Mandato & $\begin{array}{c}\text { Apetecer; demandar; desear; ordenar; } \\
\text { pedir; querer; requerir. }\end{array}$ \\
\cline { 2 - 4 } & Causativo & General & Haber; ocurrir; suceder. \\
\cline { 2 - 4 } & \multirow{2}{*}{ Cancia } & General & Hacer. \\
\hline
\end{tabular}




\begin{tabular}{|c|c|c|c|}
\hline \multirow{2}{*}{ Proceso material } & \multirow{2}{*}{ Cambio } & Creación & Crear; hacer. \\
\cline { 3 - 4 } & & Consumo & Alimentar; comer; consumir; invertir. \\
\cline { 2 - 4 } & Hecho & Actividad & Actuar; atender; trabajar. \\
\hline
\end{tabular}

\subsection{Motivos para la subjetividad}

Una noción teórica que introduce el concepto de subjetividad lo es el que refiere a la enunciación. Esta última es pieza fundamental en las interacciones locutor-lenguacontexto, ya que al efectuarse la enunciación, la actividad discursiva es materializada, por cuanto se activa el funcionamiento discursivo del sujeto; con ello, las estructuras enunciativas comparten la propiedad de funcionar a nivel de la frase -además del vocablo- y, a su vez, derivar de una operación de «apropiación de la lengua por el sujeto» (Bronckart, 1985, p. 253).

Para los anuncios publicitarios, la subjetividad se manifiesta tanto en la selección y disposición de estructuras gramaticales, así como en la capacidad de persuasión por la vía de la argumentación, lo cual puede explicar cómo las selecciones léxicas hechas por los hablantes configuran las estrategias pragmáticas (potencialmente factibles) para la inscripción y actuación del emisor incluyendo el receptor. A este respecto, Rojí Menchaca (s/f) sostiene que: "Todo enunciado se caracteriza por una tensión que se establece entre las aspiraciones a la objetividad y a la subjetividad de sus componentes".

La inserción de la persona ha sido enfocada, para los anuncios publicitarios que integran el corpus de esta investigación, atendiendo a seis recursos lingüísticos estratégicos empleados en la construcción de la identidad y la alteridad discursiva, es decir, el forjamiento de la o las imágenes (representaciones) que el hablante construye aludiendo a sí o a terceros. Así, siguiendo los procedimientos pautados, se tiene como "Estimación de la Subjetividad en Anuncios Publicitarios", aquellos propuestos por Massi (1998), los cuales son resumidos:

1. La selección pronominal: la presentación del yo. "Yo"

- yo: pronombre personal.

- ser/estar: verbos en presente del modo indicativo (soy/estoy); en futuro del indicativo (seré/estaré); o futuro incondicional (sería/estaría).

- me: pronombre en casos acusativo o dativo.

- mi: pronombre 0 adjetivo posesivo. 


\section{El interlocutor: tú/usted.}

- Referencia extendida: no apunta a un interlocutor concreto.

- Referencia encubierta: tú/usted no hace referencia al 'otro' en forma unívoca, sino que 'encubre' al propio hablante y es generalizable a cada uno de los receptores/oyentes/lectores.

- Referencia explícita: el pronombre alude directamente al receptor/ oyente/lector.

3. El otro o los otros: él/ellos.

- Ellos = "Ellos inclusivo" equivale a un "Nosotros encubierto", lo cual se traduce en la sentencia: "Tú, que podrías ser como Yo, podrías además ser como Ellos, como los prestigiosos, afortunados, distinguidos... como Nosotros."

\section{Yo + los otros: Nosotros.}

5. Nosotros genérico: su utilización permite al receptor materializar su inclusión en un conjunto más amplio, que incluye a todos los posibles 'protagonistas' del acto de habla: yo/tú - usted/nosotros/ustedes/ellos.

6. Nosotros exclusivo: la selección del nosotros exclusivo establece límites, demarca territorios, y de este modo, crea un efecto de distanciamiento mediante la fórmula: "Yo + Ellos - Tú".

\section{Metodología}

\subsection{Corpus de estudio}

Para realizar esta investigación se seleccionaron catorce (14) anuncios publicitarios anexos en una revista de circulación nacional (venezolana) y un (01) anuncio publicitario anexo en una revista de circulación extranjera (española), así se suma un total de quince (15) anuncios publicitarios sometidos a las variables de análisis abordadas en la Fundamentación Teórica.

\subsection{Variables e Indicadores de análisis}

Las variables de análisis son presentadas mediante dos etapas de análisis diferenciadas: 


\subsubsection{Criterios de selección e identificación de corpus de estudio (Tabla 3)}

Con este instrumento se organizó la información relativa a la referencia documental de cada anuncio publicitario - objeto de estudio; se procedió a: i) enumerar, ii) denominar el producto o servicio publicitario, iii) establecer fuente o referencia del anuncio publicitario y iv) codificar los anuncios publicitarios.

\begin{tabular}{|c|c|c|c|}
\hline $\mathrm{N}^{\circ}$ & $\begin{array}{c}\text { NOMBRE DEL PRODUCTO } \\
\text { PUBLICITADO }\end{array}$ & $\begin{array}{l}\text { FUENTE O REFERENCIA DEL } \\
\text { ANUNCIO PUBLICITARIO } \\
\end{array}$ & CódIGO DEL ANUNCIO \\
\hline 01 & Bebida alcohólica BAILEYS & $\begin{array}{l}\text { Revista “Todo en Domingo" No } 272 . \\
\text { Caracas, 19/12/2004. Encartado } \\
\text { dominical del diario El Nacional. }\end{array}$ & Anunc_Pub_001 \\
\hline 02 & $\begin{array}{l}\text { Servicio telefónico } \\
\text { MULTIPHONE }\end{array}$ & $\begin{array}{l}\text { Revista “Todo en Domingo" No } 272 . \\
\text { Caracas, 19/12/2004. Encartado } \\
\text { dominical del diario El Nacional. }\end{array}$ & Anunc_Pub_002 \\
\hline 03 & $\begin{array}{l}\text { Bebida nutricional } \\
\text { MORESCO }\end{array}$ & $\begin{array}{l}\text { Revista "Vivir Feliz" } N^{\circ} 16 . \text { Madrid, junio } \\
\text { de } 2002 .\end{array}$ & Anunc_Pub_003 \\
\hline 04 & Canal de televisión HISTORIA & $\begin{array}{l}\text { Revista "La aventura de la Historia". Año } \\
\text { 9. } N^{\circ} 103 . \text { Madrid. }\end{array}$ & Anunc_Pub_004 \\
\hline 05 & $\begin{array}{l}\text { Revista de publicidad } \\
\text { PRODUCTO }\end{array}$ & $\begin{array}{l}\text { Revista PRODUCTO. Mercadeo/ } \\
\text { Comunicación/Publicidad. Caracas, año } \\
\text { 24. N } \text { N }^{\circ} \text { 290, p. } 15 \text { (Enero 2008). }\end{array}$ & Anunc_Pub_005 \\
\hline 06 & $\begin{array}{l}\text { Restaurant Marisquería } 7 \\
\text { Mares }\end{array}$ & $\begin{array}{l}\text { Revista PRODUCTO. Mercadeo/ } \\
\text { Comunicación/Publicidad. Caracas, año } \\
\text { 24. } N^{\circ} 290 \text {, p. } 29 \text { (Enero 2008). }\end{array}$ & Anunc_Pub_006 \\
\hline 07 & Gimnasio GYMPLUS & $\begin{array}{l}\text { Revista PRODUCTO. Mercadeo/ } \\
\text { Comunicación/Publicidad. Caracas, año } \\
\text { 24. N } \text { N }^{\circ} 290, \text { p. } 65 \text { (Enero 2008). }\end{array}$ & Anunc_Pub_007 \\
\hline 08 & Crucero ROYAL CARIBBEAN & $\begin{array}{l}\text { Revista PRODUCTO. Mercadeo/ } \\
\text { Comunicación/Publicidad. Caracas, año } \\
\text { 24. N }{ }^{\circ} 290, \text { p. } 101 \text { (Enero 2008). }\end{array}$ & Anunc_Pub_008 \\
\hline 09 & $\begin{array}{l}\text { Empresa de vidrios OWENS } \\
\text { - ILLINOIS }\end{array}$ & $\begin{array}{l}\text { Revista PRODUCTO. Mercadeo/ } \\
\text { Comunicación/Publicidad. Caracas, año } \\
\text { 23. } \mathrm{N}^{\circ} 280 \text {, p. } 5 \text { (Marzo 2007). }\end{array}$ & Anunc_Pub_009 \\
\hline 10 & $\begin{array}{l}\text { Fundación DANIELA } \\
\text { CHAPPARD }\end{array}$ & $\begin{array}{l}\text { Revista PRODUCTO. Mercadeo/ } \\
\text { Comunicación/Publicidad. Caracas, año } \\
\text { 23. } N^{\circ} 280 \text {, p. } 32 \text { (Marzo 2007). }\end{array}$ & Anunc_Pub_010 \\
\hline 11 & $\begin{array}{l}\text { Fundación DANIELA } \\
\text { CHAPPARD }\end{array}$ & $\begin{array}{l}\text { Revista PRODUCTO. Mercadeo/ } \\
\text { Comunicación/Publicidad. Caracas, año } \\
\text { 23. } \text { N}^{\circ} 280 \text {, p. } 32 \text { (Marzo 2007). }\end{array}$ & Anunc_Pub_011 \\
\hline
\end{tabular}




\begin{tabular}{|c|c|c|c|}
\hline 12 & $\begin{array}{l}\text { Fundación DANIELA } \\
\text { CHAPPARD }\end{array}$ & $\begin{array}{l}\text { Revista PRODUCTO. Mercadeo/ } \\
\text { Comunicación/Publicidad. Caracas, año } \\
\text { 23. } N^{\circ} 280, \text { p. } 33 \text { (Marzo 2007). }\end{array}$ & Anunc_Pub_012 \\
\hline 13 & $\begin{array}{l}\text { Fundación DANIELA } \\
\text { CHAPPARD }\end{array}$ & $\begin{array}{l}\text { Revista PRODUCTO. Mercadeo/ } \\
\text { Comunicación/Publicidad. Caracas, año } \\
\text { 23. } N^{\circ} 280 \text {, p. } 33 \text { (Marzo 2007). }\end{array}$ & Anunc_Pub_013 \\
\hline 14 & $\begin{array}{l}\text { Supermercados EXCELSIOR } \\
\text { GAMA }\end{array}$ & $\begin{array}{l}\text { Revista “Todo en Domingo" No } 284 . \\
\text { Caracas, 13/03/2005. Encartado } \\
\text { dominical del diario El Nacional. }\end{array}$ & Anunc_Pub_014 \\
\hline 15 & Bebida láctea LOS ANDES & $\begin{array}{l}\text { Revista “Todo en Domingo" No } 278 . \\
\text { Caracas, 30/01/2005. Encartado } \\
\text { dominical del diario El Nacional. }\end{array}$ & Anunc_Pub_015 \\
\hline
\end{tabular}

\subsubsection{Instrumento de segmentación y organización de datos. Variables de análisis de transitividad (Tabla 4)}

Mediante esta tabla de discriminación de categorías se consideró el registro en cada anuncio publicitario atendiendo a los siguientes criterios:

\begin{tabular}{|c|c|c|c|c|c|c|c|c|c|c|}
\hline \multirow[b]{2}{*}{ 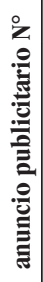 } & \multirow[b]{2}{*}{ Texto } & \multirow[b]{2}{*}{$\begin{array}{l}0 \\
\text { 总 } \\
\text { S. }\end{array}$} & \multirow[b]{2}{*}{$\begin{array}{l}\text { Esquema } \\
\text { sintáctico }\end{array}$} & \multirow[b]{2}{*}{$\begin{array}{l}\text { Tipo de } \\
\text { oración }\end{array}$} & \multicolumn{4}{|c|}{ Verbo } & \multicolumn{2}{|c|}{ Sujeto } \\
\hline & & & & & 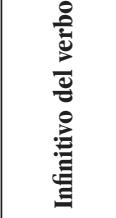 & 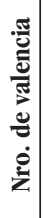 & 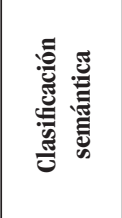 & 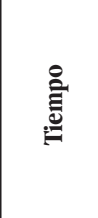 & 产 & 营 \\
\hline \multirow[b]{2}{*}{1} & Su sabor... provoca. & 1 & $\mathrm{SUJ}-\mathrm{V}-(\mathrm{OD})$ & Transitiva & Provocar & 2 & Causativo & Presente & Singular & $3^{\circ}$ \\
\hline & Déjate llevar por tus sentidos. & 2 & $\begin{array}{l}(\mathrm{SUJ})-\mathrm{V}-\mathrm{OD} \\
- \text { OPREP }\end{array}$ & Transitiva & $\begin{array}{l}\text { Dejar ＋ } \\
\text { (llevar) }\end{array}$ & 3 & Causativo & Presente & Singular & $2^{\circ}$ \\
\hline 2 & $\begin{array}{l}\text { En esta navidad, hable sin límite } \\
\text { con sus familiares y amigos, } \\
\text { desde su casa, a Venezuela y el } \\
\text { Mundo. }\end{array}$ & 1 & $\begin{array}{l}(\mathrm{SUJ})-\mathrm{V}-\mathrm{OD} \\
-\mathrm{CM}-\mathrm{CCOMP} \\
-\mathrm{CL}-\mathrm{CT}\end{array}$ & Transitiva & Hablar & 3 & Existencia & Presente & Singular & $2^{\circ}$ \\
\hline \multirow{3}{*}{3} & $\begin{array}{l}\text { Desde tiempos ancestrales, } \\
\text { las grandes culturas se han } \\
\text { alimentado de los recursos } \\
\text { naturales de la tierra. }\end{array}$ & 1 & $\mathrm{SUJ}-\mathrm{V}-\mathrm{CAG}$ & $\begin{array}{l}\text { Intransitiva } \\
\text { [Pasiva] }\end{array}$ & Alimentar & 2 & Cambio & Presente & Plural & $3^{\circ}$ \\
\hline & $\begin{array}{l}\text { MORESCO recupera esta sana } \\
\text { alimentación y // te ofrece los } \\
\text { mejores frutos en forma de } \\
\text { bebida. }\end{array}$ & 2 & \begin{tabular}{|l|}
$\mathrm{SUJ}-\mathrm{V}-\mathrm{OD}$ \\
$(\mathrm{SUJ})-\mathrm{V}-\mathrm{OD}$ \\
$-\mathrm{OI}-\mathrm{CMODO}$
\end{tabular} & $\begin{array}{l}\text { Transitiva } \\
\text { Transitiva }\end{array}$ & $\begin{array}{l}\text { Recuperar } \\
\text { Ofrecer }\end{array}$ & $\begin{array}{l}2 \\
3\end{array}$ & $\begin{array}{l}\text { Cambio } \\
\text { Posesión }\end{array}$ & $\begin{array}{l}\text { Presente } \\
\text { Presente }\end{array}$ & $\begin{array}{l}\text { Singular } \\
\text { Singular }\end{array}$ & $\begin{array}{l}3^{\circ} \\
3^{\circ}\end{array}$ \\
\hline & $\begin{array}{l}\text { Tu cuerpo adquirirá las mejores } \\
\text { vitaminas de la Tierra y la energía } \\
\text { del Sol. }\end{array}$ & 3 & SUJ $-\mathrm{V}-\mathrm{OD}$ & Transitiva & Adquirir & 2 & Cambio & Futuro & Singular & $3^{\circ}$ \\
\hline
\end{tabular}




\begin{tabular}{|c|c|c|c|c|c|c|c|c|c|c|}
\hline \multirow{5}{*}{4} & He vivido todas las épocas. & 1 & $(\mathrm{SUJ})-\mathrm{V}-\mathrm{OD}$ & Transitiva & $\begin{array}{l}\text { Haber }+ \\
\text { (vivir) }\end{array}$ & 2 & Existencia & Presente & Singular & $1^{\circ}$ \\
\hline & $\begin{array}{l}\text { He vivido } 1000 \text { batallas y // } \\
\text { sobrevivido a todas ellas, firmado } \\
\text { cientos de tratados de paz y } \\
\text { // hablado con toda clase de } \\
\text { hombres. }\end{array}$ & 2 & $\begin{array}{l}(\mathrm{SUJ})-\mathrm{V}-\mathrm{OD} \\
(\mathrm{SUJ})-\mathrm{V}- \\
\text { OPREP } \\
(\mathrm{SUJ})-\mathrm{V}-\mathrm{OD} \\
(\mathrm{SUJ})-\mathrm{V}- \\
\text { OPREP }\end{array}$ & $\begin{array}{l}\text { Transitiva } \\
\text { Intransitiva } \\
\text { Transitiva } \\
\text { Intransitiva }\end{array}$ & $\begin{array}{l}\text { Haber + } \\
\text { Part. } \\
\text { Haber + } \\
\text { Part. } \\
\text { Haber + } \\
\text { Part. } \\
\text { Haber + } \\
\text { Part. }\end{array}$ & $\begin{array}{l}2 \\
2 \\
2 \\
2\end{array}$ & $\begin{array}{l}\text { Existencia } \\
\text { Existencia } \\
\text { Existencia } \\
\text { Existencia }\end{array}$ & Presente & Singular & $1^{\circ}$ \\
\hline & $\begin{array}{l}\text { He pasado por el mundo, } \\
\text { observando, aprendiendo, } \\
\text { sintiendo cada época como si } \\
\text { fuera la mía. }\end{array}$ & 3 & $\begin{array}{l}(\mathrm{SUJ})-\mathrm{V}-\mathrm{CL} \\
-\mathrm{CM}\end{array}$ & Intransitiva & $\begin{array}{l}\text { Haber + } \\
\text { Participio }\end{array}$ & 2 & Existencia & Presente & Singular & $1^{\circ}$ \\
\hline & $\begin{array}{l}\text { Y aún me queda tanto por ver, // } \\
\text { escuchar, // por vivir. }\end{array}$ & 4 & $\begin{array}{l}\mathrm{V}-\mathrm{OD}-\mathrm{OI}- \\
\text { CTIEMPO } \\
\mathrm{V}-(\mathrm{OD})- \\
(\mathrm{OI}) \\
\mathrm{V}-(\mathrm{OD})- \\
(\mathrm{OI})\end{array}$ & $\begin{array}{l}\text { Transitiva } \\
\text { Transitiva } \\
\text { Transitiva }\end{array}$ & Quedar & 3 & $\begin{array}{l}\text { Atribución } \\
\text { Atribución } \\
\text { Atribución }\end{array}$ & Presente & Singular & $1^{\circ}$ \\
\hline & Soy inmortal. & 5 & $\begin{array}{l}(\mathrm{SUJ})-\mathrm{V}- \\
\text { ATRIB }\end{array}$ & Intransitiva & Ser & 1 & Atribución & Presente & Singular & $1^{\circ}$ \\
\hline 5 & $\begin{array}{l}\text { Suscríbase a la mejor revista } \\
\text { especializada de Venezuela. }\end{array}$ & 1 & $\begin{array}{l}(\mathrm{SUJ})-\mathrm{V}- \\
\text { OPREP - OI }\end{array}$ & Intransitiva & Suscribir & 3 & Atribución & Presente & Singular & $2^{\circ}$ \\
\hline
\end{tabular}

\section{A. Criterios de selección gramatical}

1. Se consideraron todas las oraciones en su tipo (incluyendo las denominadas Hendidas, y Pseudohendidas).

2. Las oraciones subordinadas fueron consideradas como constituyentes oracionales. En consecuencia, los marcadores discursivos (alocuciones discursivas) también se calificaron como elementos extraoracionales.

3. Todas las oraciones se estimaron como "simples" (sin excepción de su forma y función). En algunos casos, se tomaron oraciones coordinadas como una sola unidad estructural; no obstante, persistió la exhaustividad en la segmentación oracional a fin de examinar detalladamente el registro de frecuencia de uso de las variables de transitividad y subjetividad.

4. En lo que concierne a la transitividad, la orientación metodológica se diferencia del criterio expuesto por García-Miguel (1995), se asumió no la función sintáctica del verbo como predicado, sino que se distinguió al verbo dentro de la estructura del predicado, asignándosele además la nomenclatura (V). 
a. Se han considerado además, a efectos de la presencia de transitividad, tanto los elementos circunstantes (circunstanciales) y facultativos u obligatorios (complemento adverbial, suplemento, etc.)

b. Las variables de transitividad e intransitividad fueron organizadas mediante esquemas sintácticos tomados de Vázquez Rozas y García- Miguel (2005). Véase Matriz 3 - Tabla 3.

c. Las nomenclaturas asumidas corresponden a las siguientes denominaciones:

i. $\quad$ SUJ $=$ Sujeto

ii. $\quad \mathrm{V}=$ Verbo

iii. $\mathrm{OD}=$ Objeto directo

iv. $\quad$ OI $=$ Objeto indirecto

v. $\mathrm{CADV}=$ Complemento adverbial

vi. $\quad \mathrm{CPRED}=$ Complemento predicativo

vii. $\mathrm{CAG}=$ Complemento agente

viii. $\mathrm{CPREP}=$ Complemento prepositivo

ix. $\quad$ CCIRC $=$ Complemento circunstancial (de lugar, de modo, de causa, de finalidad, de instrumento, de tiempo).

d. En lo que concierne a la subjetividad, la clasificación semántica de los verbos siguió los lineamientos propuestos en "Lista provisional de clases verbales en ADESSE ("Alternancias de Diátesis y Esquema Sintáctico Semánticos del Español")"; no obstante, se atendió solo a las categorías contenidas en "Clase". Igualmente, se consideró para la categoría de "Sujeto" (gramatical), las variables "Número" (singular o plural) y "Persona" $\left(1^{\circ}, 2^{\circ}\right.$ y $3^{\circ}$ del singular 0 del plural). Este criterio reforzó la estimación de la subjetividad, o inserción de la persona en los anuncios publicitarios.

\section{B. Criterios de segmentación}

Se consideró el concepto tradicional de "oración ortográfica": aquella cuya extensión comprende los límites establecidos de mayúscula a punto, o a signo de puntuación (punto y coma; dos puntos o, en algunos casos, coma). 


\section{Resultados}

\subsection{Variable: intransitividad}

El total de casos de oraciones intransitivas, registradas en anuncios publicitarios, suma 27 coincidencias de aparición. El esquema sintáctico más frecuente de los anuncios analizados es: [SUJ - V - CPRED] con un total de 11 coincidencias (frecuencia absoluta) y un alcance de $40,74 \%$ respecto al $100 \%$ ( 827 repeticiones). En contraste con el total de casos, tanto intransitivos como transitivos, que corresponde a 56, el esquema sintáctico referido ocupa un $19,64 \%$ de frecuencia relativa porcentual. Otro caso destacado de oraciones intransitivas lo ocupa el esquema sintáctico [SUJ - V], con un total de 6 coincidencias y un alcance de $22,22 \%$ respecto al total de 27 casos intransitivos, y un registro de $10,71 \%$ en contraste con el total de 56 casos intransitivos y transitivos.

\subsection{Variable: transitividad}

El total de casos de oraciones transitivas, registradas en anuncios publicitarios, suma 29 coincidencias de aparición. El esquema sintáctico más frecuente de los anuncios analizados es: [SU - V - OD] con un total de 11 coincidencias (frecuencia absoluta) y un alcance de $37,93 \%$ respecto al $100 \%$ (29 repeticiones). En contraste con el total de casos, tanto intransitivos como transitivos, que corresponde a 56, el esquema referido ocupa un $19,64 \%$ de frecuencia relativa porcentuada. Otro caso destacado de oraciones intransitivas lo ocupa el esquema sintáctico [SUJ - V - OD - CCIRC], con un total de 10 coincidencias y un alcance de $34,48 \%$ respecto al total de 29 casos transitivos, y un registro de $17,85 \%$ en contraste con el total de 56 casos intransitivos y transitivos.

Se acota que, en cifras porcentuales, los esquemas sintácticos intransitivos ocupan un total de $46,4 \%$ de registros de uso; mientras que los esquemas sintácticos transitivos ocupan un $51,76 \%$ de registros de uso.

\subsection{Clases semánticas de verbos (según ADESSE)}

De un total de 56 casos (oraciones analizadas), se registraron dos clases verbales, las cuales reunieron notables cifras de frecuencias de aplicación. La primera clase verbal corresponde a aquellos coincidentes con cualidades de "Atribución", registrando 16 coincidencias (frecuencia absoluta) y un $28,57 \%$ de frecuencia relativa porcentual; vale aclarar que los indicadores de clase precisaron verbos relacionados con "parecer", "semejar" y "ser". La segunda clase verbal corresponde a aquellos coincidentes con cualidades de "Existencia", registrando 15 coincidencias (frecuencia absoluta) y un $26,78 \%$ de frecuencia relativa porcentual; cabe anotar que los indicadores de clase precisaron verbos relacionados con "haber", "ocurrir", "suceder". 


\subsection{Inserción de la persona}

\subsection{1 "Yo"}

De un total de 56 casos (oraciones analizadas), se registraron para el uso de la primera persona del singular "yo" -conjunto con sus variantes alomórficas tratados en la fundamentación teórica- 14 coincidencias de inserción representando esta cifra un $25 \%$ del total porcentual. Vale mencionar que esta categoría ocupó el segundo lugar de preferencia de uso en anuncios publicitarios -objeto de estudio.

\subsection{2 "Tú/Usted"}

De un total de 56 casos (oraciones analizadas), se registraron, para el uso de la segunda persona del singular "tú/usted", 16 coincidencias de inserción representando esta cifra un $28,57 \%$ del total porcentual. Esta categoría ocupó el primer lugar de preferencia de uso en anuncios publicitarios - objeto de estudio.

\subsubsection{Inserción de la persona: "Él / Ella"}

De un total de 56 casos (oraciones analizadas), se registraron, para el uso de la tercera persona del singular "él/ella", 13 coincidencias de inserción representando esta cifra un 23,21\% del total porcentual. Esta categoría ocupó el tercer lugar de preferencia de uso en anuncios publicitarios - objeto de estudio.

Se advierte que estas tres primeras categorías abarcan un parcial de 43 casos respecto al 56 del total de frecuencias, lo cual comprende un parcial porcentual de $76,78 \%$; es decir, aproximadamente $4 / 6$ ("cuatro sextos") considerando que la categoría "Nosotros exclusivo" no registró ninguna frecuencia de uso y que la última categoría "Ellos inclusivo" $(16,07 \%)$, y la categoría "Nosotros inclusivo" recabó solo un 7,14\% del total porcentual.

\section{Consideraciones finales}

El estudio efectuado de la transitividad y la subjetividad, y la injerencia que la una posee sobre la otra, permite apuntar algunas consideraciones en torno de los anuncios publicitarios seleccionados para su examen:

1. A nivel pragmático y discursivo, los usos de los anuncios publicitarios persiguen los siguientes objetivos:

a. Comunicación rápida y eficaz con los receptores.

b. Implicar, por la vía de la persuasión, a los receptores.

c. Exaltar y ponderar las propiedades o atributos de los productos anunciados. 
2. A nivel morfo-sintáctico, los usos de estructuras gramaticales y su incorporación en las oraciones que conforman los mensajes de los anuncios contribuyen a forjar la transitividad en las mismas. En este sentido, se enumeran las siguientes observaciones:

a. Construcciones nominales: con predominio de aposiciones (especificativas y explicativas) en oraciones combinadas.

b. Amplias expansiones del sintagma nominal.

c. Oraciones de infinitivo independientes: con el fin de reforzar tonos sentenciosos y subrayar rasgos esenciales del producto o servicio promocionado.

d. Empleo predominante del predicativo y del adjetivo adverbializado: lo cual anula la utilización del adverbio con terminación -mente.

e. Las preferencias oracionales registran tendencia a la oración simple y a la yuxtaposición. Entre las oraciones subordinadas, son notorias las comparativas y las consecutivas.

f. La implicación del receptor/comprador/consumidor: se efectúa mediante la atención a su conducta condicionada a un futuro inmediato. La función apelativa se configura como la principal función de la comunicación publicitaria. En este sentido, se destacan:

i. Oraciones imperativas: aplicadas al esquema "imperativo" + "futuro", con ello, se establece una correspondencia entre la apelación al consumo y las consecuencias provechosas que de él se derivan.

ii. Oraciones enunciativas: implican mucho más a los receptores, por cuanto se les incluye en afirmaciones categóricas sobre preferencias o apetencias y efectos 0 atribuciones del producto o servicio publicitado.

g. Fórmula de tratamiento: cambiantes y adaptables de acuerdo con el tipo de producto anunciado y el tipo de receptor al cual se dirige. Pueden mediar además entre el trato distante $o$ el trato aproximativo mediante la persona predilecta "tú/usted".

h. Empleo de la reflexividad: implicación de los receptores en la acción verbal.

i. Alta frecuencia en el registro de uso de esquemas sintácticos intransitivos acompañados de complementos predicativos.

j. Baja frecuencia en el registro de uso de esquemas sintácticos transitivos acompañados de objeto directo, objeto directo + complementos circunstanciales, y objeto directo + objeto indirecto. 
k. Preeminencia de la distinción de cualidades o atribuciones por el emisor/ publicista hacia el receptor/comprador (parecer; semejar; ser). De igual manera, preeminencia de sustantivos y adjetivos relativos al condicionamiento de la existencia del receptor/comprador (haber; ocurrir; suceder).

\section{Referencias bibliográficas}

Bronckart, J. P. (1985). Teorías del Lenguaje. Herder: Barcelona.

Ferraz M., A. (2001). El lenguaje de la publicidad. Madrid: Arco Libros.

García-Miguel, J. M. (1995). Las relaciones gramaticales entre Predicado y Participantes. Colección Lalia. Series Maior $N^{\circ}$ 2. España: Universidad de Santiago de Compostela.

Massi, M. P. (1998). La reconstrucción de la identidad en el discurso del marginado. Un análisis lingüístico-discursivo. Revista Chilena de Semiótica. Recuperado de http://rehue. csociales.uchile.cl/rehuehome/facultad/publicaciones/semiotica3/semio-0.htm

Porto Dapena, J. A. (1994). Complementos argumentales del verbo: directo, indirecto, suplemento y agente. Madrid: Arco Libros.

Rojí Menchaca, B. (s/f). Punto de vista y perspectiva: La subjetividad inscrita en el discurso Recuperado de: http://dialnet.unirioja.es/servlet/articulo?codig $0=1962726$

Seco, M. (2001). Gramática esencial del español. Cuarta edición. Madrid: Espasa Calpe.

Vázquez R., V., y García-Miguel, J. M. (2005) Transitividad, subjetividad y frecuencia de uso en español. Recuperado de: http://webs.uvigo.es/weba575/jmgm /public/NazquezRozazGarciaMiguel_CLG7.pdf 